\title{
COMPARISON OF ORAL HEALTH STATUS AND BEHAVIORS BETWEEN CHILDREN WITH AUTISTIC SPECTRUM DISORDER AND HEALTHY CHILDREN IN RASHT CITY, IRAN
}

\section{ABSTACT}

Objectives: In this study, the caries experience, gingivitis and behaviors of 6-12 year old children with Autistic Spectrum Disorder (ASD) were investigated according to the Frankl scale during dental examination, and then compared with healthy children.

Materials and Methods: Totally, 55 children with ASD (including 49 males and 6 females) and 165 healthy children (including 83 males and 82 females) were assessed in Rasht, Iran. Before clinical examination, their parents were asked to complete a questionnaire consisting of several questions about parental education level, nutritional status and oral hygiene status. The number of decayed, missing and filled teeth, gingival status and behaviors of the children were recorded during the dental examination. The obtained data were analyzed using Chi-square and Mann Whitney U Test. P-value less than 0.05 was considered statistically significant.

Results: Our results implied that the children with ASD had higher DMFT/dmft scores compared with healthy children $(p<0.001)$. Also, the prevalence of localized and generalized gingivitis was higher in children with ASD than that in healthy children $(\mathrm{p}=0.014)$. Most of the children with ASD behaved in negative or definitely negative manner during dental examination ( $\mathrm{p}=0.001)$. The results showed that the mean level of parental education and oral hygiene habits (such as frequency of brushing and flossing) in healthy children were higher than that in the children with ASD.

Conclusions: According to the results, the children with ASD had higher caries experience and gingivitis compared with healthy children and most of them behaved in negative or definitely negative manner during dental examination.

Keywords: Autistic disorder, dental caries, gingivitis, child.
Seyedeh Hediyeh DANESHVAR ${ }^{1}$

Alaleh KAVIANFAR ${ }^{2}$

DSeyed Hossein MASOOMI ${ }^{3}$

(D) Mir Mahdi DANESHVAR ${ }^{4}$

ORCID IDs of the authors:

S.H.D. $0000.0002-5002-2350$

A.K. $\quad 0000-0002-1294-4813$

S.H.M. 0000-0002-3981-5114

M.M.D. 0000-0003-4213-3867

1 Dental Sciences Research Center, Department of Pediatric Dentistry, School of Dentistry, Guilan University of Medical Sciences, Rasht, Iran

${ }^{2}$ School of Dentistry, Guilan University of Medical Sciences, Rasht, Iran

3 Student Research Committee, Dental Research Center, School of Dentistry, Guilan University of Medical Sciences, Rasht, Iran

4 Postgraduate Student, Department of Prosthodontics Dentistry, School of Dentistry, Guilan University of Medical Sciences, Rasht, Iran.

Received : 25.10 .2019

Accepted : 15.01 .2020

How to Cite: Daneshvar SH, Kavianfar A, Masoomi S.H, Daneshvar M.M. Comparison of Oral Health Status and Behaviors Between Children with Autistic Spectrum Disorder and Healthy Children in Rasht City, Iran. Cumhuriyet Dent J 2020;23:1;38-44. 


\section{INTRODUCTION}

Autism Spectrum Disorder (ASD) as a neurodevelopment disorder is characterized by repetitive patterns of behaviors and major impairment in social communication. ASD was first described in 1943 by Leo Kanner. This disorder is classified into five subtypes: (a) autism disorder, (b) asperger's syndrome, (c) rett's disorder, (d) childhood disintegrative disorder and (e) pervasive developmental disorder. ${ }^{1}$ ASD as a common disorder has a population prevalence of 6 cases in 1000 children. This disorder is considered as an important cause of morbidity and mortality worldwide. ${ }^{2}$ Regardless of the age of the children, ASD interventions should improve all difficulties and challenges in relation to this disorder such as gastrointestinal disturbances, attention deficit hyperactivity disorder (ADHD), learning disability, anxiety and depression, sleep disturbances, sensory sensitivity and motor difficulties. ${ }^{3}$ It has been well known that ASD is a multifactorial psychiatric condition and a combination of three developmental, environmental and genetic factors is introduced as the etiology of this disorder. ${ }^{4}$ Boys are 3.7 times more likely to be autistic than girls. ${ }^{5}$ Early signs of autism appear in infants as young as 6 months. The signs of this disorder are then stabilized by age 2-3 years, and then tend to continue through adulthood. It has been reported that there are certain problems and obstacles preventing autistic patients from receiving adequate professional dental care, and in most cases the dental needs of these children are ignored. Previous studies have reported controversial outcomes on prevalence of dental caries in children with ASD compared with healthy children. ${ }^{6-9}$ Some literatures ${ }^{4,6,10}$ have reported that the prevalence of dental caries and periodontal problems in children with ASD is higher than that in healthy children due to the lack of ability to learn and perform oral hygiene habits such as brushing and flossing. By contrast, some other studies ${ }^{11-13}$ have showed a lower dental caries in children with ASD due to good supervision of their parents regarding tooth brushing. Therefore, the results of these studies are not comparable and conclusive about oral health status of children with ASD. Hence, the present study aimed to evaluate oral health status and behaviors of children with ASD during dental examination and to compare them with healthy children in Rasht, Iran.

\section{MATERIALS AND METHODS}

In this cross-sectional case control study, 55 children with ASD (49 males and 6 females) were selected from autism rehabilitation center of Rasht city as the case group. Also, 165 healthy children (83 males and 82 females) were selected from children referred to the Dentistry faculty of Guilan University of Medical Science, Rasht, Iran, as the control group. Inclusion criteria were an age in the range 6-12 years old and having a diagnosis of ASD for the case group. Exclusion criteria included poor cooperation, having other disorders and parental dissatisfaction. Ethical approval (IR.GUMS.REC.1397.333) for this study was obtained from ethics committee of the Guilan University of Medical Sciences and Autism Rehabilitation Center prior to oral examination. In the both case and control groups, their parents were informed about the procedure and objectives and the informed written consent was obtained.

The parents were asked to complete a questionnaire containing questions about parental education level, nutritional status and oral hygiene status of the children. The severity of ASD was categorized into three levels including mild, moderate and severe based on the impairments in communication, social interaction and repetitive behaviors by a physician ${ }^{1}$. The oral examinations of the children were performed by pediatric dentist using Tell-Show-Do technique. The oral examinations were conducted using a dental mirror and explorer under natural light. The dentist recorded all decayed teeth (D/d), missing teeth $(\mathrm{M} / \mathrm{m})$ (due to caries) and all filled teeth (F/f) (including primary and permanent teeth) in accordance with WHO guidelines (1997). ${ }^{14}$

Gingival status was recorded as generalized or localized gingival inflammation depending on the amount of gingival redness and bleeding during the examination according to the gingival index of Loe and Silness. ${ }^{15}$ During dental examination, behavioral status of patients was also evaluated based on Frankl scale. ${ }^{16}$ Bruxism was recorded 
based on the observation of wear facets as an indication of enamel and dentin attrition. ${ }^{17}$ During the examination, their parents/trainers were present to make them feel more comfortable and informed about the dental treatment needs of their children.

\section{Statistical Analysis}

Statistical analysis was carried out using SPSS software (version 21). Descriptive statistics were reported as mean \pm standard deviation for quantitative variables. The frequencies and percentages were used for qualitative variables. Chi-square statistic test was used to analyze the data obtained regarding the children's ages, oral habits, Frankl's behavior scale score, bruxism and gingivitis. Mann-Whitney $\mathrm{U}$ test was also applied to compare the caries experience between the two case and control groups. A statistically significant level was considered at $\mathrm{p}<0.05$.

\section{RESULTS}

In the present study, 55 autistic and 165 healthy children were selected as the case and control groups, respectively. The mean age of the children in the study and control groups were $9.32 \pm 2.33$ and $8.71 \pm 1.97$, respectively. There was no significant difference between the two means $(\mathrm{p}=0.085) .89 .1 \%$ of participants in the case group and $50.3 \%$ of them in the control group were male. (Table 1)

Table 1. Demographic status, parental education level, nutrition status and oral hygiene habits of children with ASD and healthy children

\begin{tabular}{|c|c|c|c|c|c|c|}
\hline \multicolumn{2}{|c|}{ Parameters } & \multicolumn{2}{|c|}{ Children with ASD } & \multicolumn{2}{|c|}{ Healthy children } & \multirow[t]{2}{*}{ P-value } \\
\hline \multirow{3}{*}{ Gender } & & $\mathrm{N}$ & $\%$ & $\mathrm{~N}$ & $\%$ & \\
\hline & Male & 49 & 89.1 & 83 & 50.3 & 0.001 \\
\hline & Female & 6 & 10.9 & 82 & 49.7 & \\
\hline \multirow[t]{3}{*}{ Age } & $6-7 \mathrm{yr}$ & 19 & 34.5 & 73 & 44.2 & 0.360 \\
\hline & $8-9$ yrs & 10 & 18.2 & 31 & 18.8 & \\
\hline & 10 and above & 26 & 47.3 & 61 & 37 & \\
\hline \multicolumn{2}{|c|}{ Age $($ Mean \pm SD $)$} & \multicolumn{2}{|c|}{$9.32 \pm 2.33$} & \multicolumn{2}{|c|}{$8.71 \pm 1.97$} & 0.085 \\
\hline \multirow[t]{3}{*}{ Dentition } & Primary & 11 & 20 & 28 & 17 & 0.125 \\
\hline & Mixed & 24 & 43.6 & 97 & 58.8 & \\
\hline & Permanent & 20 & 36.4 & 40 & 24.2 & \\
\hline \multirow[t]{3}{*}{ Father's education } & Elementary & 10 & 18.2 & 11 & 6.7 & 0.034 \\
\hline & High school & 28 & 50.9 & 87 & 52.7 & \\
\hline & University degree & 17 & 30.9 & 67 & 40.6 & \\
\hline \multirow{3}{*}{ Mother's education } & Elementary & 12 & 21.8 & 13 & 7.9 & 0.014 \\
\hline & High school & 24 & 43.6 & 75 & 45.5 & \\
\hline & University degree & 19 & 34.5 & 77 & 46.7 & \\
\hline \multirow[t]{3}{*}{ Frequency of sweet consumption } & Low & 30 & 54.5 & 91 & 55.15 & 0.110 \\
\hline & Moderate & 16 & 29.1 & 62 & 37.6 & \\
\hline & High & 9 & 16.4 & 12 & 7.3 & \\
\hline \multirow[t]{2}{*}{ Dental floss use } & No & 55 & 100 & 135 & 81.8 & 0.001 \\
\hline & Yes & 0 & 0 & 30 & 18.2 & \\
\hline \multirow{3}{*}{$\begin{array}{c}\text { Brushing frequency } \\
\text { (per day) }\end{array}$} & Does not brush & 19 & 34.5 & 6 & 3.6 & 0.001 \\
\hline & Once & 30 & 54.5 & 86 & 52.1 & \\
\hline & Twice or more & 6 & 10.9 & 73 & 44.2 & \\
\hline
\end{tabular}

The education level of the fathers $(\mathrm{p}=0.034)$ and mothers $(\mathrm{p}=0.014)$ in control group was significantly higher than that in the case group. There were no differences between the ASD and control groups in terms of frequency of sweet consumption $(\mathrm{p}=0.11)$ (Table 1$)$.

The results implied that in the ASD group, none of the children were using dental floss, while in the control group, $18.2 \%$ of participants were using dental floss $(\mathrm{p}=0.001)$. The rate of tooth brushing in the ASD group was significantly less than that in the control group $(\mathrm{p}=0.001)$. These results are presented in Table 1.

The prevalence of gingivitis $(\mathrm{p}=0.014)$ and bruxism $(\mathrm{p}=0.001)$ in children with ASD was significantly higher than that in the healthy group (Table 2). 
Table 2. Behavioral status during dental examination according to Frankl scale, gingival status and bruxism in children with ASD and healthy children.

\begin{tabular}{|c|c|c|c|c|c|c|}
\hline \multirow[t]{2}{*}{ Parameters } & & \multicolumn{2}{|c|}{ Children with ASD } & \multicolumn{2}{|c|}{ Healthy children } & \multirow[t]{2}{*}{ P-Value } \\
\hline & & $\mathrm{N}$ & $\%$ & $\mathrm{~N}$ & $\%$ & \\
\hline \multirow{4}{*}{ Frankl scale } & Negative & 26 & 47.3 & 4 & 2.4 & \multirow{4}{*}{0.001} \\
\hline & Definitely negative & 21 & 38.2 & 0 & 0 & \\
\hline & Positive & 8 & 14.5 & 68 & 41.2 & \\
\hline & Definitely positive & 0 & 0 & 93 & 56.4 & \\
\hline \multirow{3}{*}{ Bruxism } & No & 24 & 43.6 & 159 & 96.4 & \multirow{3}{*}{0.001} \\
\hline & Yes & 31 & 56.4 & 6 & 3.6 & \\
\hline & Non & 23 & 41.8 & 91 & 55.2 & \\
\hline \multirow[t]{2}{*}{ Gingivitis } & localized & 23 & 41.8 & 66 & 40 & \multirow[t]{2}{*}{0.014} \\
\hline & Generalized & 9 & 16.4 & 8 & 4.8 & \\
\hline
\end{tabular}

According to Frankl's behavior rating scale, the healthy children were more likely to behave in positive or definitely positive manner during dental examination compared with the ASD group. There was a statistically significant difference between the two groups $(\mathrm{p}=0.001)$ (Table 2).

As presented in Table 3, the children with ASD had higher DMFT/dmft scores compared with healthy children $(\mathrm{p}=<0.001)$.

Table 3.Comparison of number of decayed, missing and filled teeth between children with ASD and healthy children.

\begin{tabular}{cccccc}
\hline Parameters & \multicolumn{2}{c}{ Children with ASD } & \multicolumn{2}{c}{ Healthy children } & P-value \\
\hline & Mean \pm SD & median & Mean \pm SD & Median & \\
DMFT+dmft & $6.33 \pm 2.88$ & 6 & $3.88 \pm 2.91$ & 4 & $<0.001$ \\
Decayed teeth $(\mathbf{D + d})$ & $5.78 \pm 3.21$ & 6 & $2.48 \pm 2.69$ & 2 & $<0.001$ \\
Missing teeth $(\mathbf{M + m})$ & $0.11 \pm 0.42$ & 0 & $0.13 \pm 0.44$ & 1 & $<0.001$ \\
Filled teeth $(\mathbf{F + f})$ & $0.44 \pm 1.07$ & 0 & $1.27 \pm 1.62$ & 1 & $<0.001$ \\
\hline
\end{tabular}

In this regard, a statistically significant difference was observed in the mean numbers of decayed, missing and filled teeth between the case and control groups $(\mathrm{p}=<0.001)$. The results showed that the mean number of decayed teeth in children with ASD was higher than that of the healthy children, while the mean numbers of missing and filled teeth in the ASD group was lower than that in healthy children.
Our findings implied that there were no significant difference in caries experiences between children with ASD and healthy children. So that, no significant difference was observed in primary and mixed dentition between the two groups $(\mathrm{p}=0.06)$. The DMFT score in permanent dentition in children with ASD was significantly higher than that of healthy children $(p=<0.001)$ (Table 4).

Table 4. Comparison of caries experiences in permanent, primary and mixed dentition in children with ASD and healthy children.

\begin{tabular}{|c|c|c|c|c|c|}
\hline \multirow[t]{2}{*}{ Parameters } & \multicolumn{2}{|c|}{ Children with ASD } & \multicolumn{2}{|c|}{ Healthy children } & \multirow[t]{2}{*}{ P-Value } \\
\hline & Mean \pm SD & Median & Mean \pm SD & Median & \\
\hline $\begin{array}{l}\text { Permanent dentition } \\
\text { (DMFT) }\end{array}$ & $6.20 \pm 2.75$ & 6 & $2.7 \pm 2.6$ & 2 & $<0.001$ \\
\hline $\begin{array}{l}\text { Primary dentition } \\
\text { (dmft) }\end{array}$ & $6.45 \pm 3.50$ & 7 & $4.43 \pm 2.87$ & 4 & 0.06 \\
\hline $\begin{array}{l}\text { Mixed dentition } \\
\text { (DMFT+dmft) }\end{array}$ & $6.38 \pm 2.81$ & 6 & $4.22 \pm 2.93$ & 4 & 0.06 \\
\hline
\end{tabular}

Table 5 presents the relationship between ASD severity and DMFT/dmft scores. As observed, the mean score of DMFT/dmft in the children with severe ASD was higher than that in the children with mild and moderate ASD ( $\mathrm{P}=0.007)$.

Table 5. Relationship between ASD severity and caries experiences (DMFT+dmft).

\begin{tabular}{cccc}
\hline Disorder severity & N & \multicolumn{1}{c}{ DMFT+dmft } & P-Value \\
\hline & & Mean \pm SD & 6 \\
Mild & 17 & $5.59 \pm 2.74$ & 5 \\
Moderate & 27 & $5.78 \pm 2.71$ & 0.007 \\
Severe & 9 & $8.78 \pm 2.05$ & 8 \\
\hline
\end{tabular}




\section{DISCUSSION}

ASD is a developmental disorder that can affect oral health status of people with this disorder. Most of previous studies have focused on the awareness of ASD. While few studies have investigated oral health status in children with ASD. This cross-sectional study assessed the dental caries experiences, behavioral and gingival status of 6-12 year old children with ASD in comparison with healthy children in Rasht city, Iran.

In the present study, $\mathrm{M} / \mathrm{F}$ ratio was $8: 1$, which indicated that the boys are at a higher risk for having ASD. This finding is in agreement with all previous studies around the world. ${ }^{10,11}$ The higher prevalence of this disorder among males suggests an $\mathrm{x}$-linked disorder, involving up to 20 interacting genes. It is believed that children born with a genetic vulnerability to autism, are sensitive to external environmental factors. In this disorder, parental environmental factors include taking antidepressants during pregnancy, maternal viral infections and nutritional deficiency, especially folic acid deficiency. Some other factors have been also addressed such as extremely low birth weight and neonatal anemia. $10,18,19$

Children with ASD suffer from poor muscle coordination and tend to consume sweet and soft food. They are more likely to keep their food in oral cavity instead of swallowing due to oral motor deficiencies. These nutritional problems lead to increased risk of dental caries in these children. Drugs that are used by these children to control the symptoms of this disorder, can cause xerostomia and subsequently make the patient more susceptible to dental caries. ${ }^{5}$ Some literatures reported that the prevalence of dental caries in children with ASD is higher than that in healthy children. ${ }^{4,6,10}$

Suhaib et al. ${ }^{4}$ reported that the high rate of dental caries experience among ASD children is attributed to inability or irregular brushing habits. Some studies showed that children with ASD have lower prevalence of dental cariess. ${ }^{11-13}$ This finding can be attributed to the good oral health care supervision by their parents and using carbohydrate-restricted diets. Sarnat et al. ${ }^{11}$ concluded that the lower dental caries in children with ASD is a result of a decreased consumption of sweet snacks.

Shapira et al. ${ }^{20}$ found lower caries prevalence and severe periodontal problems in these patients. Tharapiwattananon et al. ${ }^{21}$ showed that half of the children with ASD had dental caries and poor oral hygiene, and the caries may lead to early tooth loss in these children and subsequently causes malocclusion. Desai et al..$^{22}$ also reported a higher prevalence of dental caries in children with ASD.

In this study, children with ASD had more untreated dental caries compared with healthy children, and the number of extracted and filled teeth in healthy children were more than children with ASD. These results could be due to poor dental awareness and poor cooperation of these children with dentists. On the other hand, the parents of children with ASD are often exhausted for constant supervision, feeding, bathing and the children are unable to follow oral hygiene instructions. In addition, inadequate training of dentists and dental specialists, and high sensitivity of these children to unfamiliar sounds, lights, odors and colors are the barriers to access their dental care. ${ }^{23}$

Namal et al. ${ }^{13}$ reported that children with ASD had more extracted permanent teeth compared with healthy children. It is believed that extraction in children with ASD is preferred due to the challenging nature of their management.

There was no significant difference in frequency of sweet consumption between the children with ASD and healthy groups. These results are consistent with findings of previous studies conducted in Pakistan ${ }^{4}$ and Egypt. ${ }^{23}$

Bruxism is one of the relatively common oral health problems in children with ASD. ${ }^{24,25}$ In this study, $56.4 \%$ of the children with ASD and 3.6\% of the healthy children had bruxism. In Önol S et $a l .{ }^{26}$ study, in the western mediterranean region of turkey, $41.3 \%$ of children with ASD and $5.4 \%$ of children without ASD had bruxism. El Khatib AA et $a .^{23}$ reported a higher prevalence of occlusal 
facets, as an indication of bruxism, in children with ASD $(\mathrm{p}=<0.001)$

During dental examination, children with ASD showed more uncooperative behaviors compared with the healthy children, which is in agreement with Marshall et al., study ${ }^{27}$, in which $65 \%$ of children with ASD were uncooperative. It has been suggested that the behavioral management should involve gradual desensitization to familiarize these children with basic dental instruments and procedures. ${ }^{23}$

The results of the gingival status of children with ASD showed that $41.8 \%$ and $16.4 \%$ of them had localized and generalized gingivitis, respectively. In Jaber MA study ${ }^{6}$ in the United Arab Emirates, 97\% of children with ASD had gingivitis, which was generalized in $78 \%$ of the cases and localized in $22 \%$ of the studied cases.

According to the results obtained, the oral hygiene and gingival status of children with ASD were significantly poorer than that of healthy children, which could be attributed to irregular brushing, lack of ability to brush and side-effects of medications used to control the symptoms of this disorder. ${ }^{11}$

\section{CONCLUSIONS}

The above discussion emphasizes the fact that the children with ASD had a higher prevalence of caries and gingivitis with poor cooperation during dental examination compared with healthy children. Therefore, comprehensive oral health educational programs should be implemented for their parents to prevent dental and oral diseases in the children with ASD. With regard to the increase of the number of children with ASD in recent years, it is essential to implement effective training programs to raise the awareness of dentists about the problems of these children, and to provide better dental services for them.

\section{ACKNOWLEDGEMENTS}

We would like to thank Autism Rehabilitation Center of Rasht for their great support.

\section{CONFLICT OF INTEREST}

The authors declare no conflict of interest.

\section{REFERENCES}

1. Magoo J, Shetty AK, Chandra P, Anandkrishna L, Kamath PS, Iyengar U. Knowledge, attitude and practice towards oral health care among parents of autism spectrum disorder children. J Adv Clin Res Insights $2015 ; 2: 82-86$.

2. Simonoff E, Pickles A, Charman T, Chandler S, Loucas T, Baird G. Psychiatric disorders in children with autism spectrum disorders: prevalence, comorbidity, and associated factors in a populationderived sample. J Am Acad Child Adolesc Psychiatry 2008; 47:921-929.

3. Elder JH, Kreider CM, Brasher SN, Ansell M. Clinical impact of early diagnosis of autism on the prognosis and parent-child relationships. Psychol Res Behav Manag 2017; 10:283-292.

4. Suhaib F, Saeed A, Gul H, Kaleem M. Oral assessment of children with autism spectrum disorder in Rawalpindi, Pakistan. Autism 2019; 23:81-86.

5. Chandrashekhar S, Bommangoudar JS. Management of Autistic Patients in Dental Office: A Clinical Update. Int J Clin Pediatr Dent 2018; 11:219-227.

6. Jaber MA. Dental caries experience, oral health status and treatment needs of dental patients with autism. J Appl Oral Sci 2011; 19:212-217.

7. Delli K, Reichart PA, Bornstein MM, Livas C. Management of children with autism spectrum disorder in the dental setting: concerns, behavioural approaches and recommendations. Med Oral Patol Oral Cir Bucal 2013; $18: \mathrm{e} 862$.

8. Karaaslan F, Dikilitaş A, Yiğit U. Oral Health Status and Associated Factors in a Subpopulation of Turkish Patients. Cumhuriyet Dent J 2019; 22(2):167175.

9. Altın KT, Alp F, Aydın SN, Çıldır ŞK, Sandallı N. Improvement of Oral Health Status in a Group of Students with Visual Impairment in Istanbul. Cumhuriyet Dent J 2019; 22(1):83-91.

10. Reka Vishnu C, Arangannal P, Shahed H. Oral health status of children with autistic disorder in channai. Eur Arch Paediatr Dent 2012; 13:126-131.

11. Sarnat H, Samuel E, Ashkenazi-Alfasi N, Peretz B. Oral health characteristics of preschool children with 
autistic syndrome disorder. J Clin Pediatr Dent 2016; 40:21-25.

12. Subramaniam P, Gupta M.Oral health status of autistic children in India. J Pediatr Dent 2011;36 :43-46.

13. Namal N, Vehit H, Koksal S. Do autistic children have higher levels of caries? J Indian Soc Pedod Prev Dent 2007; 97-102.

14. World Health Organization. Oral Health Surveys. Basic method. $4^{\text {th }}$ ed. Geneva:WHO;1997.

15. Loe H, Silness J. The gingival index, the plaque index and the retention index systems. J Periodontal 1967;41:41-43.

16. Frankl SN, Shiere FR, Fozeles HR. Should the parent remain with the child in the dental operatory? J Dent Child 1962;29:150-163.

17. Knight DJ, Leroux BG, Zhu C, Almond J, Ramsay DS. A longitudinal study of tooth wear in orthodontically treated patients. Am J Orthod Dentofac Orthop 1997;112:194-202.

18. Newschaffer CJ, Croen LA, Daniels $J$ et al. the epidemiology of autism spectrum disorders. Annu Rev Public Health 2007; 28:235-258.

19. Geier, Kern, Geier. A prospective study of oxidative stress biomarkers in autistic disorders. Electronic J Applied Psychology 2009; 5(1): 2-10.
20. Shapira J, Mann J, Tamari I, Mester R, Knobler H, Yoeli Y, Newbrun E. Oral health status and dental needs of an autistic population of children and young adults. Spec Care Dentist 1989;9:38-41.

21. Tharapiwattananon T. Autistic child and dental management. Cu Dent J 1994;17:1-10.

22. Desai M, Messer LB, Calache H. A study of the dental treatment needs of children with disabilities in Melbourne, Australia. Aust Dent J 2001;46:41-50.

23. El Khatib AA, El Tekeya MM, El Tantawi MA, Omar T. Oral health status and behaviours of children with Autism Spectrum Disorder: a case-control study. Int J Paediatr Dent 2014;24:314-323.

24. Gandhi RP, Klein U. Autism spectrum disorders: an update on oral health management. J Evid Based Dent Pract 2014;14:115-126.

25. Muthu MS, Prathibha KM. Management of a child with autism and severe bruxism: a case report. J Indian Soc Pedod Prev Dent 2008;26:82.

26. Önol S, Kırzıoğlu Z. Evaluation of oral health status and influential factors in children with autism. Niger J Clin Pract 2018;21:429-435.

27. Marshall J, Sheller B, Williams BJ, Mancl L, Cowan C. Cooperation predictors for dental patients with autism. Pediatr Dent 2007;29:369-376. 